\section{Cureus}

\title{
Correlation Between Body Mass Index and Dental Caries Among Three- to 12-Year-Old Schoolchildren in India: A Cross-Sectional Study
}

Kavitha Swaminathan ${ }^{1}$, Vasanthakumari Anandan ${ }^{2}$, SelvaKumar Haridoss ${ }^{1}$, Eapen Thomas ${ }^{3}$

1. Pedodontics and Preventive Dentistry, Sri Ramachandra Institute of Higher Education and Research, Chennai, IND 2. Paediatric Dentistry, Adhiparasakthi Dental College and Hospital, Melmaruvathut, IND 3. Pediatric Dentistry, Dr. Sunny Medical Centre, Sharajah, ARE

Corresponding author: Kavitha Swaminathan, kadva28@gmail.com

\section{Abstract}

Introduction: Diet is a deeply ingrained element of a person's life. Children's dietary habits are a significant contributor to obesity and dental caries. Dental caries during childhood continues to be a significant public health concern, while childhood obesity is increasingly being cited as a major public health problem. This study aimed to assess the correlation between body mass index (BMI) and dental caries in children aged three to 12 years who attended both government and private schools in Chennai, Tamil Nadu, India.

Materials and methods: We conducted a cross-sectional review of 2200 children aged three to 12 years with clinically recorded dental caries. The World Health Organization diagnostic criteria for BMI percentile was used to evaluate and record dental caries clinically. The MannWhitney and the Kruskal-Wallis tests were used for univariate comparisons.

Results: Mean values between the overweight category and underweight category revealed no significant differences.

Conclusion: We found no association between BMI-for-age and dental caries in children in both primary and mixed dentition. This relationship should be investigated further by longitudinal studies.

Categories: Miscellaneous, Other, Dentistry

Keywords: obesity, school children, over weight, dental caries, body mass index

Received 07/30/2019

Review began 08/12/2019

Review ended 08/15/2019

Published 08/18/2019

C Copyright 2019

Swaminathan et al. This is an open access article distributed under the terms of the Creative Commons Attribution License CC-BY 3.0., which permits unrestricted use, distribution, and reproduction in any medium, provided the original author and source are credited.

\section{Introduction}

Obesity and dental caries are multifactorial conditions, both having comprehensive etiology and factors such as dietary habits and available nutrients, oral hygiene, or saliva [1]. Studies have shown that excessive food intake or inadequate physical activity are underlying causes of obesity [2]. The interaction of genetic, environmental, and behavioral factors could lead to childhood obesity has been reported [3]. Changes in diet and lifestyle, such as an increase in wealth and access to carbohydrate-rich, high-calorie food and drinks could be attributed to the increase in the prevalence of both dental caries and obesity [4]. The prevalence of obesity has increased in a magnitude of two to five times in developed countries, and almost four times in developing countries [5]. Several studies to date have evaluated the relationship between tooth 
decay and obesity; however, results are sometimes contradictory [6-9]. Although some studies have reported that the prevalence of obesity in India is high, its relationship with dental caries appears to be scant $[10,11]$. Hence, this study assessed the correlation between age-specific body mass index (BMI) and dental caries in children aged three to 12 years.

\section{Materials And Methods}

A cross-sectional observational study was conducted among school-going children aged three to 12 years in Chennai, India. Both government and private schools were chosen for the study so that children from all socioeconomic levels would be covered. Ethical approval and safeguarding of all principles of the Helsinki declaration were obtained from the Sri Ramachandra Institute of Higher Education and Research in Chennai. Written informed consent for involvement in the study was obtained from each child's parent or guardian.

One government and one private school were randomly selected, and a pilot study was conducted. The prevalence of dental caries was $69 \%$ as observed in our pilot study, based on which the sample size was determined (1067) using the Epi Info ${ }^{\mathrm{TM}}$ Version 6 (Centers for Disease Control and Prevention, Atlanta, US) statistical package at 95\% confidence interval. Eight schools (four government and four private schools) were included in the study, and all children from each class were examined. Thus, 2200 children aged three to 12 years were examined. The children were then divided into two groups based on their age: Group I Primary Dentition (ages three to five years) and Group II Mixed Dentition (ages six to 12 years).

Children with long-standing systemic illness, physical or mental disability or those under any medication within the past two months were excluded from the study. A trained examiner - a person qualified for clinical assessment during numerous educational and clinical sessions in the Department of Pedodontics and Preventive Dentistry - examined the children for the presence of dental caries. All instruments were sterilized and packed (one pack per sample) in sufficient quantities for each day of work.

Children were instructed to stand straight, and their height and weight were recorded while wearing light clothing and no shoes. Height was measured using a standard height chart and weight using an analog weighing scale. All findings were entered in a data sheet for further analysis.

BMI was calculated using the height and weight recorded, and the formula used to calculate BMI was weight in $\mathrm{kg} /$ (height in $\mathrm{m} 2$ ).

Children in each age group were further divided into four subgroups based on their BMI-forage-as developed by the National Centre for Health Statistics in collaboration with the National Centre for Chronic Disease Prevention and Health Promotion: 1) underweight, meaning a BMIfor-age less than the fifth percentile; 2) normal, meaning a BMI-for-age greater than or equal to the fifth percentile and less than the 85th percentile; 3) at risk of overweight, meaning a BMIfor-age greater than the 85th percentile but less than the 95th percentile; and 4) overweight, meaning a BMI-for-age greater than the 95th percentile [12]. None of the children in this study belonged to the "at risk of overweight" category; therefore, this group was omitted.

The evaluation of dental caries was followed by diagnostic criteria suggested by the World Health Organization (WHO) [13]. A modified WHO proforma was used to record data regarding the general information and Dunning type III clinical examination was used for examination [14]. An intraoral examination was done visually with the aid of a mouth mirror and probe, and the findings were recorded as decayed, missing, or filled using the (decayed-missing-filled teeth $[D M F T] /$ decayed- extracted-filled teeth [DEFT]) index. Since children were in different stages of 


\section{Cureus}

the mixed dentition, naturally exfoliated primary teeth were not taken into consideration.

Kappa statistic was used to determine the intra-examiner reproducibility, which was 0.85 . The intra-examiner reproducibility was assessed by asking the teacher to randomly select five students who were examined the preceding day, and these children were reinspected.

The data collected were tabulated and analyzed using SPSS for Windows, Version 13.0. (SPSS Inc., Chicago, US). However, one-way analysis of variance and Kruskal-Wallis tests were used for correlating obesity and dental caries; $p<0.05$ was considered statistically significant, and $p$ $<0.001$ was considered highly statistically significant.

\section{Results}

Of the total study population, 33.2\% of the children were three to five years old (Group I), and $66.8 \%$ were six to 12 years old (Group II). Of those in the three to the five-year-old group, $52.6 \%$ were boys, and $47.3 \%$ were girls, while $51.9 \%$ were boys and $48.1 \%$ were girls in the six to 12-year-old group. In Group I, $45.1 \%$ of the children attended government school, and 54.9\% attended private school, as compared to Group II, where $45.0 \%$ of the children attended government school, and $55.0 \%$ attended private school (Table 1).

\begin{tabular}{|c|c|c|c|c|c|c|c|}
\hline Group & Schools & Male (n) & $\%$ & Female (n) & $\%$ & Total (n) & $\%$ \\
\hline \multirow{3}{*}{ Group I (3-5 years) } & Government & 179 & $46.6 \%$ & 150 & $43.4 \%$ & 329 & $45.1 \%$ \\
\hline & Private & 205 & $53.4 \%$ & 196 & $56.6 \%$ & 401 & $54.9 \%$ \\
\hline & Total & 384 & $100.0 \%$ & 346 & $100.0 \%$ & 730 & $100.0 \%$ \\
\hline \multirow{3}{*}{ Group II (6-12 years) } & Government & 351 & $46.0 \%$ & 318 & $45.0 \%$ & 669 & $45.0 \%$ \\
\hline & Private & 412 & $54.0 \%$ & 389 & $55.0 \%$ & 801 & $55.0 \%$ \\
\hline & Total & 763 & $100.0 \%$ & 707 & $100.0 \%$ & 1470 & $100.0 \%$ \\
\hline
\end{tabular}

TABLE 1: Distribution of subjects according to gender and schools

Table 2 shows that among the 730 children in the three to five-year-old group, 594 (81.4\%) were in the normal weight category, 78 (10.7\%) were overweight, and 58 (7.9\%) were underweight. Among the 1470 children in the six to 12-year-old group, 958 (65.2\%) had a normal weight, 220 (14.9\%) were overweight, and 229 (19.9\%) were underweight. 


\section{Cureus}

\begin{tabular}{|c|c|c|c|c|c|c|c|}
\hline Group & BMI & Government (n) & $\%$ & Private (n) & $\%$ & Total (n) & $\%$ \\
\hline \multirow{4}{*}{ Group I (3-5 years) } & Overweight & 28 & $8.4 \%$ & 50 & $12.5 \%$ & 78 & $10.7 \%$ \\
\hline & Normal weight & 279 & $84.3 \%$ & 315 & $19.0 \%$ & 594 & $81.4 \%$ \\
\hline & Underweight & 24 & $7.3 \%$ & 34 & $8.5 \%$ & 58 & $7.9 \%$ \\
\hline & Total & 331 & $100.0 \%$ & 399 & $100.0 \%$ & 730 & $100.0 \%$ \\
\hline \multirow{4}{*}{ Group II (6-12 years) } & Overweight & 78 & $11.7 \%$ & 142 & $17.7 \%$ & 220 & $14.9 \%$ \\
\hline & Normal weight & 484 & $72.3 \%$ & 474 & $59.2 \%$ & 958 & $65.2 \%$ \\
\hline & Underweight & 107 & $16 \%$ & 185 & $23.1 \%$ & 292 & $19.9 \%$ \\
\hline & Total & 669 & $100.0 \%$ & 801 & $100 \%$ & 1470 & $100.0 \%$ \\
\hline
\end{tabular}

\section{TABLE 2: Distribution of subjects according to BMI and school category}

$\mathrm{BMI}$ - body mass index

The mean DMFT/DEFT value in Group I $(4.26 \pm 3.81)$ was significantly higher than the mean value in Group II $(2.47 \pm 2.20 ; p<0.001)$. A Mann-Whitney U test was used to calculate the $\mathrm{p}$ value (Table 3).

\begin{tabular}{|c|c|c|}
\hline Group & Mean \pm SD & p-value \\
\hline Group I (3-5 years) & $4.26 \pm 3.81$ & $<0.001$ \\
\hline Group II (6-12 years) & $2.47 \pm 2.20$ & $<0.001$ \\
\hline
\end{tabular}

TABLE 3: Mean, standard deviation and test of significance of mean values between Group I (age 3-5 years) and Group II (age 6-12 years)

SD - standard deviation

Table 4 shows BMI and dental caries in both age groups. The mean value in the overweight group was significantly lower than the normal weight group $(\mathrm{p}<0.001)$. Further, the mean value in the underweight group $(2.74 \pm 3.92)$ was significantly lower than the normal weight group $(p$ $<0.001)$. However, there was no significant difference in mean values between the overweight category and the underweight category $(\mathrm{p}=1.00)$. The Kruskal-Wallis one-way analysis of variance was used to calculate the $\mathrm{p}$-value. 


\section{Cureus}

\begin{tabular}{|c|c|c|c|c|}
\hline Group & BMI & Mean DMFT & SD & $\mathrm{p}$-value \\
\hline \multirow{3}{*}{ Group I (3-5 years) } & Overweight & 1.85 & 2.08 & \multirow{3}{*}{$<0.001$} \\
\hline & Normal weight & 4.73 & 3.81 & \\
\hline & Underweight & 2.74 & 3.92 & \\
\hline \multirow{3}{*}{ Group II (6-12 years) } & Overweight & 1.00 & 0.00 & \multirow{3}{*}{$<0.001$} \\
\hline & Normal weight & 2.42 & 2.09 & \\
\hline & Underweight & 4.41 & 3.86 & \\
\hline
\end{tabular}

\section{TABLE 4: BMI and dental caries}

BMI - body mass index

DMFT - decayed-missing-filled teeth

SD - standard deviation

\section{Discussion}

Childhood obesity is a public health problem with increasing importance in the urbanized world [15]. Being overweight/obese comes with numerous health problems [16]. Studies exploring the relationship between caries experience and BMI reported conflicting results [6-7, 17-18]. The objective of this study was to investigate the relationship between BMI and dental caries prevalence among schoolchildren aged three to 12 years.

In the present study, in both Group I (81.4\%) and Group II (65.2\%), the majority of children were in the normal weight group. In a recent obesity update, the percentage of the population with obesity by age 15 in India is 5\% whereas in the United States of America it is $38.2 \%$ [19].

Dietary deficiency occurring early in the life of a child, when the primary teeth are being formed, will enhance the occurrence of caries three to four years later [20]. The ability of a tooth to withstand caries attack is reduced if the teeth experienced nutritional harm during the essential stages of their growth [21]. Acs et al. reported that children with early childhood caries weighed significantly less than age- and sex-matched caries-free children [22]. In the present study, in Group I, underweight children showed a mean DEFT value of $2.74 \pm 3.92$, which was significantly lower than the normal weight group ( $4.73 \pm 3.81)$. In Group II, underweight children had a mean value of $4.41 \pm 3.86$, whereas normal-weight children had a lesser DMFT value of $2.42 \pm 2.09$. This difference was statistically significant in both groups.

In our study, there is no difference in caries experience between normal weight and overweight children. This finding is consistent with studies done by Tuomi [23], Chen et al. [24], Moreira et al. [7], and Assi et al. [25].

With the known culture difference, an Indian diet is different from a western diet.

Contradicting the results of our study - in which primary teeth had less caries experience in underweight children than normal-weight children - a study in Peruvian children reported that 
those who were malnourished had higher dental caries prevalence in primary dentition and delay in tooth eruption [26]. There was a positive association between obesity and dental caries in the permanent dentition but the causative direction of this relationship is unclear reported in a systemic review [27].

Our study had several limitations. Because overweight children are not very common in India, as compared to Western countries, it is difficult to collect a sufficient number of children who are overweight in a particular sample population. Moreover, the BMI values that were used were not put forth based on the Indian population. This could have resulted in a variation in the distribution of samples, as many of the normal-weight children would fall within the overweight category if the BMI values were given specific of the Indian population. Another limitation of the study, which may have underestimated caries experience, is that bitewing radiographs were not used to identify proximal caries. Initial proximal caries detected by bitewing radiographs would have altered the mean caries experience in all groups.

\section{Conclusions}

Overall caries experience is higher in primary dentition compared to the mixed dentition. Overweight children had less caries experience than the other two subgroups in both primary and mixed dentition. In the primary dentition, both underweight and overweight children had less caries experience than normal weight children. In mixed dentition, underweight children showed a greater caries experience than overweight and normal weight children. The results from this study demonstrated that no association could be assigned between BMI-for-age and dental caries; therefore, advance research is essential to addressing factors specific to overweight in children and preventing dental caries in primary and mixed dentition. A study involving a larger sample with radiographic investigations is needed in the future to further evaluate the correlation between BMI and dental caries.

\section{Additional Information}

\section{Disclosures}

Human subjects: Consent was obtained by all participants in this study. Sri Ramachandra Institute of Higher Education and Research Ethical Committee issued approval

SRUPOC/2018/1271. This research has been done as Postgradute Dissertation by Corresponding author. It has been approved by Institution Ethical Committee and Publication Oversight Committee for publication of this research. Animal subjects: All authors have confirmed that this study did not involve animal subjects or tissue. Conflicts of interest: In compliance with the ICMJE uniform disclosure form, all authors declare the following: Payment/services info: All authors have declared that no financial support was received from any organization for the submitted work. Financial relationships: All authors have declared that they have no financial relationships at present or within the previous three years with any organizations that might have an interest in the submitted work. Other relationships: All authors have declared that there are no other relationships or activities that could appear to have influenced the submitted work.

\section{References}

1. Lempert SM, Froberg K, Christensen LB, Kristensen PL, Heitmann BL: Association between body mass index and caries among children and adolescents. Community Dent Oral Epidemiol. 2014, 42:53-60. 10.1111/cdoe.12055

2. Hill JO, Wyatt HR, Peters JC: Energy balance and obesity. Circulation. 2012, 126:126-132. 10.1161/Circulationaha.111.087213

3. Zhao J, Grant SF: Genetics of childhood obesity. J Obes. 2011, 2011:845148. 10.1155/2011/845148 
4. Armfield JM, Roberts-Thomson KF, Spencer AJ: The child dental health survey, Australian 1999: trends across the 1990s. Dental Statistics and Research Series. 2003, 27:95.

5. Ogden CL, Carroll MD, Curtin LR, Lamb MM, Flegal KM: Prevalence of high body mass index in US children and adolescents, 2007-2008. JAMA. 2010, 303:242-249. 10.1001/jama.2009.2012

6. Pinto A, Kim S, Wadenya R, Rosenberg H: Is there an association between weight and dental caries among pediatric patients in an urban dental school? A correlation study. J Dent Educ. 2007, 71:1435-1440.

7. Moreira PV, Rosenblatt A, Severo AM: Prevalence of dental caries in obese and normal-weight Brazilian adolescents attending state and private schools. Community Dent Health. 2006, 23:251-253.

8. Costacurta M, DiRenzo L, Sicuro L, Gratteri S, De Lorenzo A, Docimo R: Dental caries and childhood obesity: analysis of food intakes, lifestyle. Eur J Paediatr Dent. 2014, 15:343-348.

9. Freitas AR, Aznar FD, Tinos AM, Yamashita JM, Sales-Peres A, Sales-Peres SH: Association between dental caries activity, quality of life and obesity in Brazilian adolescents. Int Dent J. 2014, 64:318-323. 10.1111/idj.12121

10. Sharma A, Hegde AM: Relationship between body mass index, caries experience and dietary preferences in children. J Clin Pediatr Dent. 2009, 34:49-52. 10.17796/jcpd.34.1.17364206hqm0477h

11. Mohan B, Kumar N, Aslam N, et al.: Prevalence of sustained hypertension and obesity in urban and rural school going children in Ludhiana. Indian Heart J. 2004, 56:310-314.

12. National Center for Health Statistics. Clinical growth charts . (2017). Accessed: July 29, 2019: https://www.cdc.gov/growthcharts/clinical_charts.htm.

13. World Health Organization: Oral health surveys: basic methods. World Health Organization. 1997. 4th ed:26-29.

14. Dunning JM: Principles of dental public health. Harvard University Press, Cambridge; 1986. 4th ed:132-133.

15. Bereket A, Atay Z: Current status of childhood obesity and its associated morbidities in Turkey. J Clin Res Pediatr Endocrinol. 2012, 4:1-7. 10.4274/jcrpe.506

16. Whitaker RC, Wright JA, Pepe MS, Seidel KD, Dietz WH: Predicting obesity in young adulthood from childhood and parental obesity. N Engl J Med. 1997, 25:869-873. 10.1056/NEJM199709253371301

17. Willershausen B, Moschos D, Azrak B, Blettner M: Correlation between oral health and body mass index (BMI) in 2071 primary school pupils. Eur J Med Res. 2007, 26:295-299.

18. Macek MD, Mitola DJ: Exploring the association between overweight and dental caries among US children. Pediatr Dent. 2006, 28:375-380.

19. OECD Health Statistics. (2019). Accessed: July 26, 2019: http://www.oecd.org/health/healthdata.htm.

20. Agarwal PK, Agarwal KN, Agarwal DK: Biochemical changes in saliva of malnourished children. Am J Clin Nutr. 1984, 39:181-184. 10.1093/ajcn/39.2.181

21. DePaola DP, Faine MP, Palmer CA: Nutrition in relation to dental medicine . Modern nutrition in health and disease. Shils EM, Olson JA, Shike M, Ross AC (ed): Williams \&Wilkins, Philadelphia; 1999. 9th ed:1099-1124.

22. Acs G, Lodolini G, Kaminsky S, Cisneros GJ: Effect of nursing caries on body weight in a pediatric population. Pediatr Dent. 1992, 14:302-305.

23. Tuomi T: Pilot study on obesity in caries prediction. Community Dent Oral Epidemiol. 1989, 17:289-291. 10.1111/j.1600-0528.1989.tb00638.x

24. Chen W, Chen P, Chen SC, Shih WT, Hu HC: Lack of association between obesity and dental caries in three-year-old children. Zhonghua Min Guo Xiao Er Ke Yi Xue Hui Za Zhi. 1998, 39:109-111.

25. Assi SP, Pires JR, Pontes AEF, Barroso EM, Zuza EP: Oral conditions and body weight in children from a public school in Manaus, AM, Brazil. Rev Odontol UNESP. 2016, 45:362-367. 10.1590/1807-2577.09816

26. Alvarez JO, Lewis CA, Saman C, et al.: Chronic malnutrition, dental caries, and tooth exfoliation in Peruvian children aged 3-9 years. Am J Clin Nutr. 1988, 48:368-372. 10.1093/ajcn/48.2.368

27. Hayden C, Bowler JO, Chambers S, et al.: Obesity and dental caries in children: a systematic review and meta-analysis. Community Dent Oral Epidemiol. 2013, 41:289-308. 


\section{Cureus}

10.1111/cdoe.12014 